\title{
A study of various factors related to satisfaction of complete denture wearers
}

\author{
Jin-Soo Byun', Yoon-Hyuk Huh², Lee-Ra Cho², Chan-Jin Park²* \\ 'Department of Prosthodontics, Wonkwang University Sanbon Dental Hospital, Gunpo, Republic of Korea \\ ${ }^{2}$ Department of Prosthodontics and Research Institute of Oral Science, College of Dentistry, Gangneung-Wonju National \\ University, Gangneung, Republic of Korea
}

\begin{abstract}
Purpose: The aim of this study was to evaluate correlations between denture satisfaction and various factors related to patients' and wearing dentures. Materials and Methods: Total 43 edentulous patients were recalled and they were wearing complete dentures fabricated more than one year ago. For patients' subjective assessment, the questionnaire based on the various literatures was developed and applied to patients for data acquisition. In addition, correlations were evaluated between subjective assessment and denture satisfaction score. For statistical analysis, Spearman correlation coefficient, multiple regression analysis, Mannwhitney $\mathrm{U}$ test and Kruskal-Wallis test were used to found out what the most considerable factors to denture satisfaction score $(P$ $<0.05)$. Results: Denture satisfaction score of maxilla was higher than mandible $(P<0.05)$. In functional aspects, maxillary denture were received a favorable evaluation. Especially fit and pain causing were highly correlated to satisfaction. Gender, age, using period, visiting times after manufacturing denture were unrelated to satisfaction. But previous experience was related to denture satisfaction. Conclusion: Denture satisfaction was determined by a combination of various factors related to patients. (J Dent Rehabil Appl Sci 2016;32(2):109-16)
\end{abstract}

Key words: complete denture; denture satisfaction; questionnaire

\begin{abstract}
서론
오랜기간 동안 무치악 환자에서 총의치는 구강의 기 능을 회복하기 위한 첫 번째 방법으로 고려되어 현재까 지 제작되어 사용되어져 왔다. 무치악 환자는 의치 사용 을 통해 정상적인 식사가 가능한 저작력, 노인성 안모의 회복, 적절한 발음 등의 삶의 질에 영향을 미치는 여러 문제를 해결하고자 한다. 무치악 환자의 높은 기대와는 다르게 여러 연구에서 다양한 연령대, 의치의 질적인 면 에 대한 만족도를 조사한 결과 $20-35 \%$ 의 환자가 불만 족스러운 평가를 내렸다. ${ }^{1-3}$ 치과의사의 술기를 제외하

*Correspondence to: Chan-Jin Park

Professor, Department of Prosthodontics and Research Institute of Oral Science, College of Dentistry, Gangneung-Wonju National University, 7 Jukheon-gil, Gangneung, 25457, Republic of Korea

Tel: +82-33-640-3153, Fax: +82-33-640-3103, E-mail: doctorcj@gwnu.ac.kr

Received: April 24, 2016/Last Revision: June 9, 2016/Accepted: June 13, 2016
\end{abstract}

고도 전적으로 환자가 지닌 구강 내외의 환경, 성격 등 의 여러 요인이 의치사용 만족도에 영향을 미치고 제작 한 의치에 대한 환자의 적응이 만족도를 평가하는데 중 요한 지표가 될 수 있으며 최종 목표로 여겨질 수 있다. 의치를 올바른 과정을 통해 제작하였고 사용되어도 불 량한 잔존 치조제, 비정상적인 악간관계 등의 여러 임 상적인 요인에 의해서 장기적인 만족도는 감소될 수 있 음은 분명하다. ${ }^{4}$ 일반적으로 의치사용에 대한 불만족은 연조직에서 발생하는 통증, 압박이나 낮은 적합도로 인 한 의치의 쉬운 탈락, 식편압입, 안모 등과 관련된 다양 한 원인에 의해 나타난다. 이와 같이 의치사용 만족도

Copyright(C) 2016 The Korean Academy of Stomatognathic Function and Occlusion. (c) This is an Open-Access article distributed under the terms of the Creative Commons Attribution Non-Commercial License (http://creativecommons.org/ licenses/by-nc/4.0) which permits unrestricted non-commercial use, distribution, and reproduction in any medium, provided the original work is properly cited. 
에 영향을 미치는 다양한 요인은 여러 문헌에서 분석되 었으나 이들 요인을 만족도와의 관련성을 알아본 결과 공통된 의견을 얻지는 못하고 다양하게 나타났다., ${ }^{3,5-8}$ 이 는 술자, 환자 그리고 제작된 의치와 관련된 여러 사항 이 복합적으로 작용함에 따른 결과로 여겨지며 의치사 용 만족도에 다양한 영향을 미친다고 볼 수 있다. 더불 어 의치를 제작하는 술자의 임상 경험에 따라 만족도가 다르게 나타날 수는 있으나 ${ }^{9}$ 환자와 관련된 정신적, 감 정적인 요인 또한 영향을 미칠 수 있기에 의치사용 만족 도에 영향을 미치는 요인을 단적으로 분석하기 어렵다 는 것이 정설로 받아들여 진다. ${ }^{10}$ 일반적으로 환자는 사 용하는 의치의 기능적 측면을 만족도의 가장 중요한 척 도로 여기며 의치의 유지력, 안정성, 적합도, 편안함 등 의 것을 포함한다. 이들 항목은 연구마다 개별적으로 제 작된 설문지를 통해 환자가 직접 답하여 평가한다. ${ }^{11-13}$ 그 외에 의치의 심미적 측면이나 저작력, 교합과 관련된 사항을 의치사용 만족도 평가에 결부시키기도 한다. ${ }^{14}$

위에 언급한 사항과 같이 복합적으로 영향을 미쳐 결 정되는 의치사용 만족도에 관한 문헌은 대부분 국외의 문헌으로 국내에서는 연구한 내용이 거의 없는 것으로 알려져 있다. 의치사용 만족도는 술자보다는 환자의 입 장에서 고려해야 하나 그에 대한 연구가 부족한 것도 사 실이다. 본 연구에서는 특정한 설문지를 제작하여 환자 에게 직접 답하게 하여 의치사용 만족도와 가장 관련이 있는 항목이 무엇인지를 알아보고 무치악 환자에서 총 의치를 제작할 때 술자가 중요하게 여겨야할 사항에 대 해 알아보고자 한다.

\section{연구 재료 및 방법}

\section{1. 연구 대상}

본 연구는 1997년 11월부터 2014년 6월까지 강릉원 주대학교 치과병원 보철과에 내원한 무치악 환자를 대
상으로 제작한 양악 총의치를 최소 1 년 이상 사용한 환 자를 대상으로 시행되었다. 내원한 환자는 보철과에서 제작한 설문지에 대한 답변을 직접 작성하였다. 기존의 진료기록부를 토대로 조사한 결과 해당기간 동안 남성 106 명, 여성 169 명으로 총 275 명의 환자를 대상으로 양 악 총의치가 제작되었고 이들의 평균 연령은 77.8 세로 나타났다.

\section{2. 연구 방법}

본 연구는 강릉원주대학교 치과병원 임상시험 심사 위원회의 승인을 득하였다(IRB 2013-11). 설문문항은 19 개의 문항으로 구성되었으며, 진료기록부에 기록된 전화번호를 이용하여 통화 후 내원 가능한 환자를 대상 으로 연구를 수행하였고 43 명의 환자가 검진에 응하였 다(Table 1).

환자에게 연구목적을 설명한 후 설문지를 배포하여 작성하게 하였으며 글을 읽지 못하거나 이해하기 어려 운 설문은 술자가 직접 설명하고 답을 기록하였다. 설문 지의 내용은 총의치를 사용할 때의 만족도를 포함하여 기능적, 심미적, 감각적인 측면의 평가로 구성하였고 의 치사용 만족도는 전반적, 상악, 하악으로 분류하였다. 또 한 환자로 하여금 기능적 측면으로 의치의 유지력과 적 합도, 편안함과 통증 발생 정도, 저작에 대한 만족도를 평가하도록 하였고 심미적 측면으로 의치상, 인공치의 색상, 형태, 배열을, 감각적 측면은 미각과 발음을 평가 하였다. 이들 항목에 대한 답은 5점 척도로 평가하여 의 치사용 만족도와의 관련성 및 중요한 요소를 알아보고 자 하였다.

\section{3. 통계 분석}

본 연구에서 측정된 결과의 통계적 유의성 검증은 SPSS 21.0 (SPSS Inc. Chicago, USA) 프로그램을 이용

Table 1. Distribution of participated sample by age and gender

\begin{tabular}{|c|c|c|c|c|c|c|c|c|}
\hline \multirow[b]{3}{*}{ Gender } & \multicolumn{8}{|c|}{ Age distribution } \\
\hline & \multicolumn{2}{|c|}{$<70$} & \multicolumn{2}{|c|}{$70-79$} & \multicolumn{2}{|c|}{$80<$} & \multicolumn{2}{|c|}{ Sum } \\
\hline & $\mathrm{N}$ & $\%$ & $\mathrm{~N}$ & $\%$ & $\mathrm{~N}$ & $\%$ & $\mathrm{~N}$ & $\%$ \\
\hline Male & 3 & 7.0 & 12 & 27.9 & 4 & 9.3 & 19 & 44.2 \\
\hline Female & 3 & 7.0 & 15 & 34.8 & 6 & 14.0 & 24 & 55.8 \\
\hline Sum & 6 & 14.0 & 27 & 62.7 & 10 & 23.3 & 43 & 100.0 \\
\hline
\end{tabular}


하여 시행하였으며 분석 결과로 얻어진 유의확률 같이 0.05 이하일 경우 통계적으로 유의하다고 평가하였고 유의한 차이가 있는 경우 사후검정을 시행하였다. 전반 적, 상악, 하악의치 사용 만족도 간의 차이는 Friedman test를 이용하여 비교평가 하였다. 그리고 항목에 해당 하는 질문 간의 일치도 판별을 위한 Cronbach $\alpha$ 를 구 한 후 의치사용 만족도 간의 연관성을 파악하기 위한 Spearman correlation coefficient 및 상관계수가 높은 항 목을 대상으로 다중회귀분석을 시행하여 만족도에 영 향을 크게 미치는 요인을 알아보고자 하였다. 환자의 성 별, 연령, 제작 횟수, 사용기간, 제작 후 내원 횟수와 같 은 다양한 항목과 관련된 사항은 Mann-Whitney U test, Kruskal-Wallis test를 시행하여 평가하였다.

\section{결과}

\section{1. 의치사용 만족도}

5점 척도로 만족도를 평가해본 결과, 전반적, 상악, 하 악 의치사용 만족도 순으로 나타났으며 이들 간에는 통 계적으로 유의한 차이가 있었다(Table 2).

\section{2. 의치의 기능 평가}

환자의 기능적 평가 문항 간의 신뢰도 평가 결과, 전체 문항, 상악, 하악 의치에 대한 문항 모두의 Cronbach $\alpha$ 신뢰계수가 0.6 이상으로 문항 간 내적 일치도를 확보하 였다. 모든 항목에서 하악보다 상악의치에 대한 기능 평 가가 더 높게 나타났다(Table 3). 또한 대부분의 기능 평 가 항목은 의치사용 만족도와 높은 상관관계를 가진다 (Table 4). 개별적인 기능적 평가 사항 중 높은 상관관계 를 가지는 항목을 선별하여 다중회귀분석을 시행한 결 과 상악의치의 적합도, 하악의치의 적합도와 통증 발현 정도가 만족도와 상대적으로 더 높은 관련이 있었다.

\section{3. 의치의 심미 및 감각 평가}

의치상, 인공치에 대한 심미평가 항목 간의 Cronbach $\alpha$ 값은 0.6 이상이었으나 미각과 발음 간에는 낮은 신 뢰도를 보였다. 의치상에 대한 심미적 만족도가 인공치 의 것보다 높았고 미각보다는 발음에 대한 만족도가 높 게 나타났다(Table 5). 의치사용 만족도는 의치의 심미 와 높은 관련성이 있었고 상대적으로 의치상의 변색, 파 절과 같은 사항이 인공치의 상태보다 더 만족도에 영향 을 미친 것으로 나타났다. 또한 미각과 발음을 비교하였 을 때 발음에 대한 만족도가 더 높았으며 상악 의치사용 만족도는 미각, 하악 의치사용 만족도는 발음과 더 높은 관련이 있었다(Table 6).

Table 2. Satisfaction score of complete denture wearers $(\mathrm{N}=43)$

\begin{tabular}{cccc}
\hline & Overall dentures & Maxillary denture & Mandibular denture \\
\hline Mean (standard deviation) & $4.47(0.59)^{\mathrm{a}}$ & $4.06(0.94)^{\mathrm{b}}$ & $3.33(1.29)^{\mathrm{c}}$ \\
\hline
\end{tabular}

Friedman test was used and different subscripts letters indicate values are significantly different, $P<0.05$.

Table 3. Patients' evaluation for denture functional qualities

\begin{tabular}{ccc}
$\begin{array}{c}\text { Functional qualities of } \\
\text { maxillary denture } \\
\text { Mean (standard deviation) }\end{array}$ & $\begin{array}{c}\text { Functional qualities of } \\
\text { mandibular denture }\end{array}$ & Statistical significance \\
\hline $4.65(0.61)$ & $3.47(1.33)$ & $*$ \\
$4.63(0.49)$ & $3.58(1.26)$ & $*$ \\
$4.56(0.50)$ & $3.23(1.23)$ & $*$ \\
$4.72(0.59)$ & $3.30(1.49)$ &
\end{tabular}

\footnotetext{
* Statistical significance test was done by Friedman test, $P<0.05$.
} 
Table 4. Correlation between patients' denture wearing satisfaction score and patients functional evaluation score

\begin{tabular}{llccc}
\hline & & Overall satisfaction & Maxillary denture satisfaction & Mandibular denture satisfaction \\
& & $\mathrm{r}$ & $\mathrm{r}$ & $\mathrm{r}$ \\
\hline Maxilla & Retention & .196 & $.340^{*}$ & $.658^{* *}$ \\
& Fitness & $.548^{* *}$ & $.419^{* *}$ & .227 \\
& Comfort & $.374^{*}$ & & $.596^{*}$ \\
& Pain & .032 & & $.736^{* *}$ \\
& Retention & $.387^{*}$ & & $.721^{* *}$ \\
& Fitness & $.525^{* *}$ & $.638^{* *}$ \\
& Comfort & $.529^{* *}$ & $.502^{* *}$ & $.580^{* *}$ \\
\hline
\end{tabular}

Spearman correlation coefficients, $* P<0.05$, ** $P<0.01$.

Table 5. Patients' evaluation of denture esthetic and sensitive aspects

\begin{tabular}{llcc}
\hline & & Mean (standard deviation) & Statistical significance \\
\hline Esthetic aspects & Denture flange & $4.14(0.77)$ & $*$ \\
& Artificial teeth & $4.02(0.80)$ & $*$ \\
Sensitive aspects & Taste & $3.93(1.03)$ & $4.37(0.72)$ \\
& Pronunciation & & $*$ \\
\hline
\end{tabular}

* Statistical significance test was done by Friedman test, $P<0.05$.

Table 6. Correlation between patients' denture satisfaction score and sensation

\begin{tabular}{|c|c|c|c|c|}
\hline & & Overall satisfaction & $\begin{array}{l}\text { Maxillary denture } \\
\text { satisfaction }\end{array}$ & $\begin{array}{c}\text { Mandibular denture } \\
\text { satisfaction }\end{array}$ \\
\hline & & $\mathrm{r}$ & $\mathrm{r}$ & $\mathrm{r}$ \\
\hline \multirow[t]{2}{*}{ Esthetic aspects } & Denture flange & $.416^{* *}$ & $.581 * *$ & $.554 * *$ \\
\hline & Artificial teeth & $.425^{* *}$ & $.491 * *$ & $.480 * *$ \\
\hline \multirow[t]{2}{*}{ Sensitive aspects } & Taste & .281 & $.466^{* *}$ & $.329 *$ \\
\hline & Pronunciation & $.339 * *$ & $.396 * *$ & $.500 * *$ \\
\hline
\end{tabular}

Spearman correlation coefficients, $* P<0.05,{ }^{* *} P<0.01$.

\section{4. 환자, 의치와 관련된 다양한 항목}

환자의 성별과 연령에 따른 의치사용 만족도는 차이 가 없는 것으로 나타났다. 의치사용 기간이 길수록 만족 도는 높은 경향을 보였으나 통계적인 차이는 없었다. 하 지만 이전에 의치를 제작하여 사용해본 경험이 있는 환 자의 전반적, 하악 의치사용 만족도가 높게 나타났으며 제작 후 정기검진이나 불편함으로 인해 내원한 횟수에 따른 만족도의 차이는 없었다(Table 7).
Table 7. Mean(standard deviation) of various factors

\begin{tabular}{lc}
\hline & Statistical significance \\
\hline Gender & - \\
Age & - \\
Previous experience & $*$ \\
Wearing period & - \\
Visiting numbers & - \\
\hline
\end{tabular}

* Statistical significance test was done by Kruskal-Wallis test, MannWhitney U test. 


\section{고찰}

본 연구는 1년 이상 의치를 사용한 환자를 대상으로 의치사용 만족도 및 만족도에 영향을 미치는 여러 요인 을 분석하여 환자가 중요시하는 사항을 알아보고자 하 였다. 전반적인 의치사용 만족도만으로 명확한 결론은 도출하는데 한계가 있다고 여겨 부가적으로 상악과 하 악 의치사용 만족도를 개별적으로 평가하였다. ${ }^{13}$ 내원한 환자는 상악, 전반적, 하악 의치 순서로 높은 만족도를 보였으며 이는 하악의 의치가 전반적인 의치사용 만족 도를 대변한다는 기존의 연구와는 상이한 결과를 보였 다. ${ }^{15}$ 본 연구를 위해 내원한 환자의 많은 수가 오랜 기간 의치를 사용하여 불편함을 느끼지 않았으며 진료기록부 를 토대로 환자와 대면 후 설문조사를 해본 결과 협조도 가 비교적 좋은 환자였다. 그 결과, 불만족스러운 답변 을 한 환자의 수가 적었던 것으로 여겨진다. 하지만 해 부학적으로 불리한 조건, 상악 의치에 비해 부족한 기능 적 측면을 지닌 하악 의치는 상대적으로 낮은 만족도를 보여 기존의 문헌에 부합하는 결과를 얻었다. ${ }^{16}$

환자는 유지력, 적합도, 편안함, 통증의 정도와 같은 의치의 기능적 항목은 상악 의치에서 더 좋은 평가를 내 렸다. 임상에서 맞이하는 대부분의 환자에서 그렇듯이 하악은 상악보다 불리한 해부학적 조건을 지니며 저작 과 관련되는 여러 요소가 상대적으로 부족한 것에 따른 결과로 여겨진다. ${ }^{17}$ 전반적인 의치사용 만족도에는 상 악 의치의 적합도와 편안함, 하악 의치의 모든 기능적 측면, 그리고 저작이 관련성이 높게 나타났다. 대부분의 환자는 상악 의치의 유지력에는 불만이 없었고 오래된 의치 하방으로의 식편압입 증상과 같은 점에 주안점을 두었다. 하지만 하악 의치의 모든 기능적 측면은 전반적 인 의치사용 만족도에 영향을 미치며 상악보다는 하악 의치제작에 더 신경써야 함을 알 수 있다. 대부분의 환 자는 상악 의치에서 발생하는 통증은 없었으며 불만을 토로하지 않았고 하악 의치로 인한 불편함이 주된 불만 사항이었기에 하악 의치에 대한 한계점과 발생하는 문 제점을 제작할 때부터 분명히 고지해야 할 것으로 여겨 진다. 무치악 환자에서 양측의 의치가 함께 작용하는 저 작은 오직 의치만으로 행해진다. 무치악 환자의 저작력 은 자연치열의 것보다 5-6배 작게 나타난다고 하나 의 치를 사용 후 시간이 지남에 따라 적응하는 과정을 통해 적절한 저작 양상을 획득함에 따라 저작 만족도가 낮은 수치로 나타나지는 않는 것으로 여겨진다. ${ }^{14}$ 본 연구 결
과는 저작에 대한 만족도가 의치사용 만족도와 관련이 있음을 나타내었으며 의치를 제작할 때 적절한 교합을 형성해주는 것이 더 나은 결과를 보일 수 있음을 나타낸 다고 볼 수 있다.

술자는 의치를 제작할 때 환자의 젊었을 때의 사진이 나 치아가 온전할 때의 사진을 통해 안모의 회복이라는 목표를 달성하고자 한다. 순, 협측의 의치상과 인공치는 안모의 구강 주위 조직이 돌출되는 정도를 결정하며 안 모와 미소선을 결정하는데 가장 중요한 역할을 한다. 의 치상과 인공치에 대한 만족도의 차이는 있으나 대부분 만족스러운 평가를 내렸고 의치를 사용하는데 있어 높 은 상관관계를 보였다. 의치의 심미적인 요소가 의치사 용 만족에 영향을 미치는 사항에 대해서는 의견이 분분 하나 ${ }^{18-20}$ 본 연구에 참여한 환자와 대화를 해본 결과, 의 치의 심미적인 요인은 시간이 흐름에 따라 환자가 둔하 게 느끼는 것으로 여겨지며 심각하게 안모에 영향을 미 치지 않는다면 대부분 불만족스러운 태도를 보이지 않 았다.

환자의 미각은 하악보다는 상악 의치의 만족도와 높 은 관련이 있었고 발음은 모든 의치사용 만족도와 높 은 상관관계를 보였다. 미각은 의치를 장착한 후 몇 주 가 지나고 환자가 새로운 의치에 적응함에 따라 점차 회 복되는 양상을 보이는데 ${ }^{21}$ 본 연구에서는 1 년 이상 의치 를 사용한 환자를 대상으로 하였기에 미각에 대한 만족 도가 높게 나타난 것으로 보인다. 발음은 구강을 구성하 는 근신경계, 타액과 깊은 관련이 있으며 이는 일정 시 간 동안의 적응기간을 거침으로써 이루어진다. ${ }^{22,23}$ 환자 는 발음에 대해 미각보다 더 높은 평가를 내렸으며 대부 분의 환자는 발음으로 인한 불편함이나 대화의 어려움 을 호소하지 않은 점이 기존의 문헌을 뒷받침하였다.

여러 문헌에서 성별과 연령에 따른 의치사용 만족도 를 알아보고자 하였다. 여성의 해부학적 조건이 불리하 지만 성별에 따른 차이가 없거나 ${ }^{3,4}$ 남성이 의치를 더 잘 받아들이거나 ${ }^{24}$ 여성이 더 민감하게 받아들인다는 문헌 이 있으나 ${ }^{25}$ 본 연구 결과는 차이가 없게 나타났다. 연령 이 증가함에 따라 환자는 의치의 한계에 체념하여 상대 적으로 더 높은 만족도를 보일 수 있으나 ${ }^{26}$ 연령에 따른 차이가 없는 기존의 문헌과 통계 처리 결과는 같으나 ${ }^{27,28}$ 평균적인 만족도는 수치적으로 전반적, 상악의치에 대 해서는 연령이 증가함에 따라 높았으며 하악의치에 대 해서는 80 세 이상에서 가장 낮은 만족도가 나타났다. 이 와 같은 결과는 상악에 비해 하악의 치조골 흡수량이 시 
간이 흐름에 따라 더 많아 무치악 환자의 연령이 증가할 수록 하악의치에 대한 만족도가 더 떨어지는 것으로 여 겨진다. ${ }^{29}$ Weinstein 등 $^{27}$ 은 3 회 이상 의치를 제작한 환자 가 그렇지 않은 환자보다 더 높은 만족도를 보인다고 하 였으며 이는 이전 의치에 대한 경험이 기대감을 낮춰줌 에 따른 결과라고 하였다. 하지만 이전의 경험이 직접적 으로 영향을 미치지 않는다는 문헌도 있으며 ${ }^{30,31}$ 본 연구 에서 전반적, 하악의치에 대한 만족도는 의치에 대해 경 험해본 환자의 수와 그렇지 않은 환자의 수의 차이가 영 향을 미쳤으리라 여겨진다. 내원한 환자와의 대화 결과, 충분히 적응한 환자는 의치의 한계를 분명히 직시하고 스스로 사용 방법을 알고 받아들임에 따라 제작 후 사용 기간, 내원 횟수에 따른 만족도의 차이가 없는 결과가 나타난 것으로 판단된다.

본 연구는 일정 비율로 군을 나눌 수 없어 정확한 비교 가 불가능한 한계를 지니며 내원한 환자의 대부분은 현 재 사용하는 의치에 대해 충분히 만족하는 경향이 있기 에 더 많은 수의 다양한 환자가 내원해야 정확한 비교가 가능할 것으로 여겨진다.

\section{결론}

의치사용 만족도는 전반적, 상악, 하악의치 순으로 나 타났으며 모든 기능적인 측면에서 상악의치에 대한 만 족도가 높게 나타났다. 특히 기능평가 항목 중 상악, 하 악의치의 적합도, 통증 발현 정도가 만족도와 높은 관련 이 있었다. 심미적인 측면에서는 의치상이 인공치보다, 감각 측면에서는 미각보다 발음이 더 만족도가 높게 나 타났으며 이들은 대부분 항목이 의치사용 만족도와 높 은 관련이 있었다. 더불어 연령, 성별, 사용기간, 장착 후 내원 횟수는 의치사용 만족도와 관련이 없었으나 이전 에 의치를 사용한 경험이 있는 환자는 전반적, 하악의치 에 대한 만족도가 높게 나타났다.

\section{ORCID}

Jin-Soo Byun http://orcid.org/0000-0001-6296-5260

Yoon-Hyuk Huh http://orcid.org/0000-0003-4072-5199

Lee-Ra Cho http://orcid.org/0000-0003-3989-2870

Chan-Jin Park http://orcid.org/0000-0003-4734-214X

\section{References}

1. Jeganathan S, Payne JA. Common faults in complete dentures: a review. Quintessence Int 1993;24: 483-7.

2. Berg E. Acceptance of full dentures. Int Dent J 1993;43:299-306.

3. Carlsson GE, Otterland A, Wennström A, Odont D. Patient factors in appreciation of complete dentures. J Prosthet Dent 1967;17:322-8.

4. Baer ML, Elias SA, Reynolds MA. The use of psychological measures in predicting patient satisfaction with complete dentures. Int J Prosthodont 1992;5:221-6.

5. Bergman B, Carlsson GE. Review of 54 complete denture wearers. Patients' opinions 1 year after treatment. Acta Odontol Scand 1972;30:399-414.

6. Smith M. Measurement of personality traits and their relation to patient satisfaction with complete dentures. J Prosthet Dent 1976;35:492-503.

7. Guckes AD, Smith DE, Swoope CC. Counseling and related factors influencing satisfaction with dentures. J Prosthet Dent 1978;39:259-67.

8. Yoshizumi DT. An evaluation of factors pertinent to the success of complete denture service. J Prosthet Dent 1964;14:866-78.

9. Kimoto S, Kimoto K, Kitamura A, Saita M, Iijima M, Kawai Y. Effect of dentist's clinical experience on treatment satisfaction of a complete denture. J Oral Rehabil 2013;40:940-7.

10. Carlsson GE. Facts and fallacies: an evidence base for complete dentures. Dent Update 2006;33:134-6, 138-40, 142.

11. Bergman B, Carlsson GE. Clinical long-term study of complete denture wearers. J Prosthet Dent 1985;53:56-61.

12. Vervoorn JM, Duinkerke AS, Luteijn F, van de Poel AC. Assessment of denture satisfaction. Community Dent Oral Epidemiol 1988;16:364-7.

13. de Baat C, van Aken AA, Mulder J, Kalk W. "Prosthetic condition" and patients' judgment of complete dentures. J Prosthet Dent 1997;78:472-8.

14. Haraldson T, Karlsson U, Carlson GE. Bite force and oral function in complete denture wearers. J Oral Rehabil 1979;6:41-8. 
15. Berg E. The influence of some anamnestic, demographic, and clinical variables on patient acceptance of new complete dentures. Acta Odontol Scand 1984;42:119-27.

16. Seifert I, Langer A, Michmann J. Evaluation of psychologic factors in geriatric denture patients. J Prosthet Dent 1962;3:516-23.

17. Slagter AP, Olthoff LW, Bosman F, Steen WH. Masticatory ability, denture quality, and oral conditions in edentulous subjects. J Prosthet Dent 1992; 68:299-307.

18. Fenlon MR, Sherriff M. Investigation of new complete denture quality and patients' satisfaction with and use of dentures after two years. J Dent 2004;32:327-33.

19. van Waas MA. The influence of psychologic factors on patient satisfaction with complete dentures. J Prosthet Dent 1990;63:545-8.

20. Smith PW, McCord JF. What do patients expect from complete dentures? J Dent 2004;32:3-7.

21. Kapur KK. A clinical evaluation of denture adhesives. J Prosthet Dent 1967;18:550-8.

22. Dragobetskii MK. The mechanisms of the adaptation of the neuromuscular apparatus to removable dentures (a review). Stomatologiia (Mosk) 1992;2: 88-90.

23. Leles CR, Compagnoni MA, de Souza RF, Barbosa DB. Kinesiographic study of mandibular move- ments during functional adaptation to complete dentures. J Appl Oral Sci 2003;11:311-8.

24. Silverman S, Silverman SI, Silverman B, Garfinkel L. Self-image and its relation to denture acceptance. J Prosthet Dent 1976;35:131-41.

25. Barenthin I. Dental health status and dental satisfaction. Int J Epidemiol 1977;6:73-9.

26. Müller F, Wahl G, Fuhr K. Age-related satisfaction with complete dentures, desire for improvement and attitudes to implant treatment. Gerodontology 1994;11:7-12.

27. Weinstein M, Schuchman J, Lieberman J, Rosen P. Age and denture experience as determinants in patient denture satisfaction. J Prosthet Dent 1988;59: 327-9.

28. Müller F, Hasse Sander I. Experimental studies of adaptation to complete dentures related to ageing. Gerodontology 1993;10:23-7.

29. Tallgren A. The continuing reduction of the residual alveolar ridges in complete denture wearers: a mixed-longitudinal study covering 25 years. J Prosthet Dent 1972;27:120-32.

30. Michman J, Langer A. Clinical and electromyographic observations during adjustment to complete dentures. J Prosthet Dent 1968;19:252-62.

31. Jonkman RE, van Waas MA, van't Hof MA, Kalk W. An analysis of satisfaction with complete immediate (over) dentures. J Dent 1997;25:107-11. 


\section{총의치 장착자의 의치 만족도와 관련된 요인에 관한 연구}

\section{변진수 ${ }^{1}$, 허윤혁 ${ }^{2}$, 조리라 ${ }^{2}$, 박찬진 ${ }^{2 *}$}

${ }^{1}$ 원광대학교 산본치과병원 치과보철과

${ }^{2}$ 강릉원주대학교 치과대학 치과보철학교실 및 구강과학연구소

목적: 본 연구는 총의치를 1년 이상 사용한 환자를 대상으로 만족도를 조사하고 이에 영향을 미치는 다양한 요인을 분 석하여 이들 간의 상관관계를 알아보고자 하였다.

연구 재료 및 방법: 총 43명의 환자가 정기검진에 응하여 내원하였다. 기존의 여러 문헌을 토대로 설문지를 제작하고 환 자로 하여금 작성하도록 하여 자료를 얻었다. 의치에 대한 환자의 주관적 평가와 의치사용 만족도 간의 상관관계를 평 가하였다. 통계 분석을 위해 Spearman 상관관계 분석, 다중회귀분석, Mann-whitney U, Kruskal-Wallis 검정법을 이용 하였다.

결과: 모든 기능적 항목에서 하악보다 상악의치에 대한 만족도가 높게 나타났으며 특히 적합도와 통증 발현 유무는 만 족도와 높은 관련이 있었다. 성별, 연령, 사용기간, 제작 후 내원 횟수는 의치사용 만족도와 관련이 없었으나 의치사용 경험이 있는 환자는 그렇지 않은 환자보다 더 높은 만족도를 보였다.

결론: 의치사용 만족도는 환자와 관련된 여러 요인이 복합적으로 작용하여 결정된다.

(구강회복응용과학지 2016;32(2):109-16)

주요어: 총의치; 의치만족도; 설문문항

*교신저자: 박찬진

(25457)강원도 강릉시 죽헌길 7, 강릉원주대학교 치과대학 치과보철학교실

Tel: 033-640-3153 | Fax: 033-640-3103 | E-mail: doctorcj@gwnu.ac.kr

접수일: 2016년 4월 24일 | 수정일: 2016년 6월 9일 || 채택일: 2016년 6월 13일 